\title{
Aplicação de Ferramentas de Geotecnologia para Quantificação Arbórea em Área Urbana
}

\section{Geotechnology Tools for Quantification of Urban Tree}

Tuane Roberta da Silva Alvez ${ }^{1}$, Thaisa Camila Vacari ${ }^{2}$, Caroline Antunes Agostinho de $\mathrm{Abreu}^{2}$, Ibraim Fantin-Cruz ${ }^{3}$

${ }^{1}$ Graduanda do Curso de Engenharia Sanitária e Ambiental - UFMT (tuaneroberta@ @otmail.com); ${ }^{2}$ Mestrandas do Curso de Pós-Graduação em Recursos Hídricos - UFMT (engcamilavacari@ gmail.com; carolagostinhoabreu@gmail.com); ${ }^{3}$ Professor do Departamento de Engenharia Sanitária e Ambiental -

UFMT (ibraimfantin@gmail.com).

Enviado: Setembro de 2014, Aceito: Outubro de 2014, Publicado: Novembro de 2014

Resumo- O presente trabalho teve como objetivo analisar e mostrar a importância de um Plano de Arborização para a cidade de Presidente Epitácio (SP). Utilizou-se como metodologia de levantamento dos dados o uso da ferramenta do Google (Google Street View), com imagens realizadas em 2011 em 68 ruas, sendo as mesmas divididas em par e ímpar. Em função de comparação do ano de 2011 para 2014, um levantamento in loco em 2014 também foi realizado, utilizando o método de avaliação em campo. Os dados foram analisados através de teste $t$ pareado comparando a densidade de árvores por sítio de amostragem. Em termos absolutos observou-se que em cada sítio, ouve um aumento no na densidade arbórea entre os anos, embora estatisticamente não significativo. Esse aumento pode ser considerado pela influencia de ações de educação ambiental, através de programas de plantio de árvores realizados nos últimos anos.

Palavras-chaves: Arborização, Google Street view, cidade Presidente Epitácio.

\begin{abstract}
This study aimed to analyze and demonstrate the importance of an Urban Tree Planting Plan for the municipality of Presidente Epitácio, State of São Paulo. Data survey was performed by using the Google Street View, with images taken in 2011 at 68 streets, divided into even and odd. For temporal comparison between 2011 and 2014, an on-site survey was also conducted in 2014, using field evaluation. Data were analyzed by paired t-test for checking the density of trees per site. In absolute terms, we observed an increase between years, but no was a significant increase in the number of trees in the city, which can be related to the influence of the actions ambinetal education, because of the numerous urban tree-planting programs in the city in recent years.
\end{abstract}

Key words: Urban tree planting, Google Street View, Presidente Epitácio City.

\section{Introdução}

Entende-se por arborização urbana, o conjunto de terras públicas e privadas, com vegetação predominantemente arbórea que uma cidade apresenta, ou ainda, é um conjunto de vegetação arbórea natural ou cultivada que uma cidade apresenta em áreas particulares, praças, parques e vias públicas (Sanchotene et al. 1994).
Dentre as inúmeras vantagens das áreas verdes, as principais são a ecológica, a estética e social (Guzzo 1999). Diversos autores relacionam essas áreas como estabilizadora de temperatura, produtoras de sombra e maior conforto térmico (Bartholomei 2003; Brito et al. 2012; Faria et al. 2013). Outro aspecto foi mencionado por Loboda e Angelis (2005), que indicou que áreas verdes públicas 
constituem elementos imprescindíveis para o bem estar da população, pois influencia diretamente a saúde física e mental da população. Além disso, é capaz de minimizar os ruídos urbanos, elevar a qualidade do ar, pois aumenta o teor de oxigênio e umidade e absorve o gás carbônico, entre outros aspectos (Platt, 1994).

Neste sentido um Plano de Arborização é imprescindível para o desenvolvimento urbano e melhoria da qualidade de vida da população das cidades. Porém para sua realização é necessário à aquisição de informações precisas que possam diagnosticar e nortear a tomada de decisões para melhoria e recuperação de áreas verdes. Neste contexto, o uso de geotecnologias vem se tornando uma ferramenta atraente para o levantamento de dados em áreas urbanas. Isso porque, o desenvolvimento tecnológico propicia um aumentado contínuo da disponibilidade de imagens de alta resolução espacial gratuitas e softwares livres (Lima 2011). Desta maneira, possibilitam maior facilidade, segurança e agilidade nas atividades humanas, referentes ao monitoramento, planejamento e tomada de decisão, relativas ao espaço geográfico.

Dentre as geotecnologias podemos destacar a cartografia digital, o sensoriamento remoto, o sistema de posicionamento global, o sistema de informação geográfica, e os aplicativos gráficos disponíveis na WEB (o Google Earth, o Microsoft Virtual Earth, Google Maps, Google Street View, etc.) (Rosa, 2011). Entre estes, o Google Maps ganha destaque por ser um serviço de pesquisa e visualização de mapas e imagens de satélite gratuito pela web, fornecido pela empresa Google. O serviço disponibiliza mapas e rotas a serem buscadas, com a possibilidade de alcançar zoom nas grandes cidades. Já o Google Street View é uma extensão do Google Maps, disponibilizado pela empresa Google em 30 de setembro de 2010, onde permita a análise dos locais com precisão através de imagens panorâmicas de $360^{\circ}$ na horizontal e $290^{\circ}$ na vertical.

Estas tecnologias têm sido utilizadas em projetos ligados ao meio ambiente, ao agronegócio, ao planejamento de negócios e também na gestão pública. $\mathrm{O}$ uso dessas ferramentas pelo poder publico ajuda no fato destes órgãos não conterem um grande número de pessoas para fiscalização.

Dentro desta perspectiva o presente trabalho teve como objetivo realizar um diagnóstico quantitativo da arborização urbana da cidade de Presidente Epitáfio (SP), nos anos de 2011 e 2014 utilizando ferramentas geotecnológicas e tradicionais para o levantamento de dados. Elencar as principais espécies utilizadas na arborização urbana, além de fornecer subsídios para o planejamento arbóreo urbano e sugestões de melhoria.

\section{Materiais e Métodos}

\section{Área de estudo}

O município de Presidente Epitácio está localizado no oeste do estado de São Paulo, na latitude $23^{\circ} 45^{\prime} 53^{\prime}$ 'S e longitude $52^{\circ} 06^{\prime} 19^{\prime \prime} \mathrm{W}$, registrando a altitude de $292 \mathrm{~m}$ em seu marco Zero. Seu território totaliza $1.260 \mathrm{~km}^{2}$ e é limitado pelo rio Paraná, divisa entre os estados de Mato Grosso do Sul e São Paulo. O clima é tropical, caracterizado por verões chuvosos e invernos secos, com temperatura média anual entre $20^{\circ}$ e $26^{\circ} \mathrm{C}$ e precipitação 
pluviométrica anual em torno de 1.300 $\mathrm{mm}$.

Figura 1: Localização da cidade de Presidente Epitácio - SP.

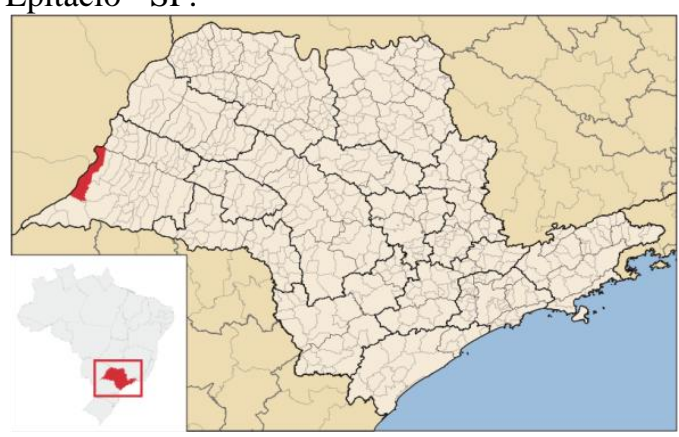

Segundo o Censo Demográfico de 2010 realizado pelo Instituto Brasileiro de Geografia e Estatística (IBGE), a população residente no município é igual a 41.318 habitantes, sendo que 2.773 residem na área rural e 38.545 na área urbana.

\section{Levantamento}

O método de levantamento foi realizado a partir da ferramenta do Google, a Google Street View, com imagens realizadas em 2011 (Figura 2).

Figura 2: Demonstração da metodologia empregada com o uso do Street View (Fonte: Google Street View, 2011).

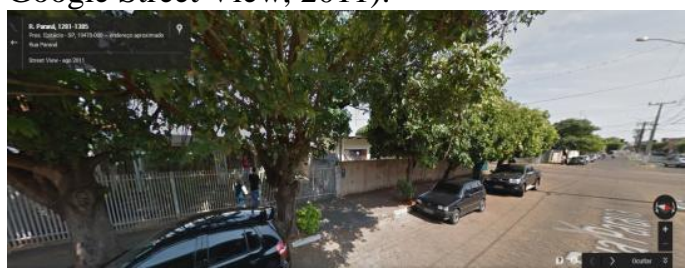

A partir dessa ferramenta, foram escolhidas 68 ruas para ser feito o levantamento, onde foram divididas em paralelas e perpendiculares, tendo como rua de referência a Avenida Presidente Vargas (Figura 3). Desta maneiras as ruas foram separadas em Lado Maceió e Lado Fortaleza, para que fossem identificadas em: Perpendiculares Lado Maceió, Perpendiculares Lado Fortaleza, Paralelas Lado Maceió e Paralelas Lado Fortaleza. O levantamento foi dividido em par e ímpar, para que pudesse ser feito quadra por quadra, sendo separadas a partir do número terminativo de cada uma destas.

Figura 3: Demonstração da metodologia empregada no levantamento arbóreo: a) ruas paralelas e b) perpendiculares à Avenida Presidente Vargas. (Fonte: Google Earth, 2011).
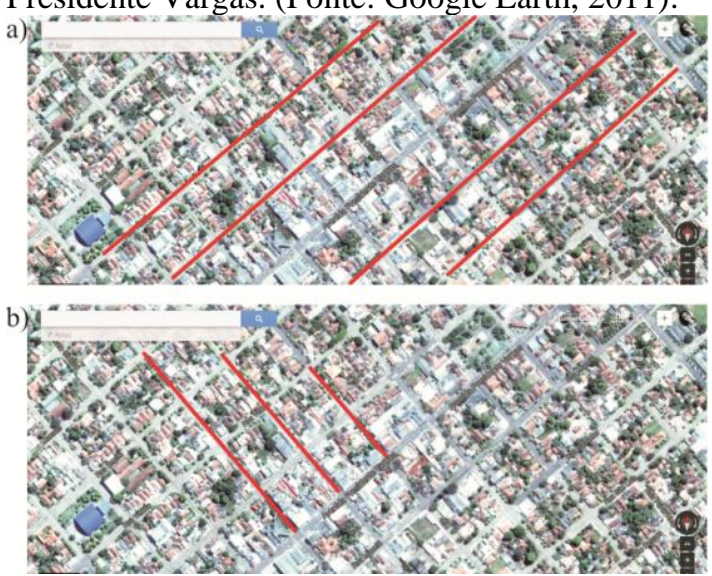

Com o intuito de comparar a evolução da arborização urbana entre os anos de 2011 e 2014 foi realizado um novo levantamento, desta vez em loco. Com a utilização de automóvel para a fácil e rápida locomoção e o auxílio de planilhas para o controle na contagem das árvores, foi percorrida todas as ruas consideradas no levantamento de 2011, seguindo a separação das quadras em par e ímpar, como foi feito no levantamento do Street View.

Após os levantamentos, foram realizadas as tabelas somando as árvores das quadras, tendo como resultados tabelas com o número de árvores por rua, de 2011 e 2014. Para tornar possível a comparar da arborização entre ruas e sítios, os resultados foram expressos em termos de densidade, mostrando o número de árvores por metro linear de rua. Com estas informações foi aplicado um teste t pareado, para verificar se a densidade de árvores por sítio de amostragem se alteraram significativamente entre os anos levantados. Este teste é recomendado quando as amostras não 
Alvez T. R. S., Vacari T. C., Abreu C. A. A., e Cruz I. F., Aplicação de Ferramentas de Geotecnologia para quantificação arbórea em área urbana. E\&S - Engineering and Science, (2014), 2:1.

são temporalmente independentes, como é este caso, já que as medidas foram feitas nas mesmas ruas.

\section{Resultados e Discussões}

A partir do levantamento realizado pela ferramenta Google Street View (2011) juntamente com o levantamento in loco (2014), observa-se que em termos absolutos que em cada sítio (Tabela 1), praticamente não houve alteração entre os anos, uma vez que, em média o número total de árvore variou apenas $\pm 4,5 \%$. No entanto, a apresentação do número de arvores em termos absolutos, impossibilita a comparação entre as ruas e a identificação das mais arborizadas. Deste modo, optou-se por padronizar o número de árvores para cada $10 \mathrm{~m}$ de rua.

\begin{tabular}{|c|c|c|c|}
\hline Logradouro & Comprimento & $\mathbf{N}^{0}$ de árvores & \\
\hline & $(\mathrm{km})$ & 2011 & 2014 \\
\hline \multicolumn{4}{|l|}{ Paralelas - Lado Maceió } \\
\hline Rua Maceió & 3.21 & 322 & 302 \\
\hline Rua Salvador & 3.42 & 424 & 416 \\
\hline Rua São Luiz & 3.42 & 449 & 444 \\
\hline Rua João Pessoa & 3.42 & 407 & 417 \\
\hline Rua Guanabara & 2.91 & 331 & 354 \\
\hline Rua Rio de Janeiro & 2.93 & 363 & 389 \\
\hline Rua Aracajú & 3.24 & 395 & 432 \\
\hline Rua Belém & 3.45 & 440 & 449 \\
\hline Rua Rio Branco & 3.17 & 299 & 332 \\
\hline Média & & 381 & 393 \\
\hline \multicolumn{4}{|l|}{ Perpendiculares - Lado Maceió } \\
\hline Rua Carlos José dos Santos & 0.78 & 42 & 62 \\
\hline Rua Major Rodrigues Bittencourt & 0.89 & 118 & 124 \\
\hline Rua Alziro Baltazar & 0.86 & 100 & 96 \\
\hline Rua Noel Rosa & 0.88 & 127 & 132 \\
\hline Rua Augusto Vincentim & 0.77 & 90 & 89 \\
\hline Rua Padre C. R. Batista & 0.88 & 86 & 87 \\
\hline Rua Emídio de Lima Paes & 0.89 & 85 & 89 \\
\hline Rua Manoel R. Filho & 0.89 & 119 & 112 \\
\hline Rua Armando Puerta & 0.89 & 99 & 105 \\
\hline Rua Professor Campos & 0.88 & 131 & 112 \\
\hline Rua José Ramos Júnior & 0.89 & 116 & 130 \\
\hline Rua Alameda das Perobas & 0.89 & 94 & 96 \\
\hline Av. Dos Ipês & 0.89 & 97 & 104 \\
\hline Rua Alameda dos Marfins & 0.88 & 110 & 116 \\
\hline Rua Iracema Carvalho de Noronha & 0.89 & 108 & 108 \\
\hline Rua Manoel Souza Barbeiro & 0.88 & 115 & 124 \\
\hline Rua Fernando Costa & 0.89 & 101 & 98 \\
\hline Rua Sebastião Ferreira dos Santos & 0.76 & 120 & 118 \\
\hline Rua Antônio Venâncio Lopes & 0.89 & 121 & 117 \\
\hline Rua Minas Gerais & 0.89 & 113 & 110 \\
\hline Rua Venceslau Brás & 0.89 & 101 & 98 \\
\hline Rua Pernambuco & 0.79 & 118 & 124 \\
\hline
\end{tabular}

Tabela 1: Quantificação arbórea realizada 2011utilizando ferramenta Google Street View e 2014 em loco nas principais ruas da cidade de Presidente Epitácio (SP). 
Alvez T. R. S., Vacari T. C., Abreu C. A. A., e Cruz I. F., Aplicação de Ferramentas de Geotecnologia para quantificação arbórea em área urbana. E\&S - Engineering and Science, (2014), 2:1.

\begin{tabular}{|c|c|c|c|}
\hline \multirow{2}{*}{ Logradouro } & \multirow{2}{*}{$\begin{array}{l}\text { Comprimento } \\
(\mathrm{km})\end{array}$} & \multicolumn{2}{|c|}{$\mathrm{N}^{\circ}$ de árvores } \\
\hline & & 2011 & 2014 \\
\hline Rua Álvaro Coelho & 0.90 & 94 & 106 \\
\hline Rua Mato Grosso & 0.89 & 108 & 109 \\
\hline Rua Paraná & 0.89 & 131 & 151 \\
\hline Rua Antônio Marinho C. P. & 0.89 & 112 & 130 \\
\hline Rua Cuiabá & 0.89 & 127 & 135 \\
\hline Rua Curitiba & 0.90 & 130 & 124 \\
\hline Rua Florianópolis & 0.90 & 142 & 144 \\
\hline Rua Porto Alegre & 0.90 & 157 & 132 \\
\hline Rua Belo Horizonte & 0.90 & 159 & 164 \\
\hline Rua São Paulo & 0.89 & 94 & 93 \\
\hline Média & & 111 & 114 \\
\hline \multicolumn{4}{|l|}{ Paralelas - Lado Fortaleza } \\
\hline Rua Fortaleza & 1.76 & 145 & 137 \\
\hline Rua Vitória & 1.90 & 249 & 232 \\
\hline Rua Recife & 1.83 & 236 & 237 \\
\hline Rua Manaus & 1.96 & 301 & 305 \\
\hline Rua Miguel Coutinho & 2.18 & 328 & 316 \\
\hline Rua Juca Pita & 2.25 & 300 & 318 \\
\hline Média & & 260 & 258 \\
\hline \multicolumn{4}{|c|}{ Perpendiculares - Lado Fortaleza } \\
\hline Rua Sebastião Novais & 0.17 & 34 & 39 \\
\hline Rua Iracema C. N. & 0.25 & 40 & 27 \\
\hline Rua Manoel S. B. & 0.35 & 61 & 60 \\
\hline Rua Jovita Ribeiro & 0.45 & 28 & 56 \\
\hline Rua Fernando Costa & 0.55 & 60 & 170 \\
\hline Rua Sebastião F. S. & 0.59 & 99 & 106 \\
\hline Rua Antônio V. L. & 0.61 & 74 & 88 \\
\hline Rua Minas Gerais & 0.61 & 63 & 68 \\
\hline Rua Venceslau Brás & 0.62 & 66 & 92 \\
\hline Rua Pernambuco & 0.61 & 70 & 73 \\
\hline Rua Álvaro Coelho & 0.62 & 37 & 71 \\
\hline Rua Mato Grosso & 0.61 & 88 & 87 \\
\hline Rua Paraná & 0.62 & 85 & 103 \\
\hline Rua Antônio M. C. P. & 0.62 & 81 & 83 \\
\hline Rua Cuiabá & 0.62 & 98 & 100 \\
\hline Rua Curitiba & 0.61 & 92 & 98 \\
\hline Rua Florianópolis & 0.62 & 84 & 77 \\
\hline Rua Porto Alegre & 0.62 & 77 & 75 \\
\hline Rua Belo Horizonte & 0.62 & 95 & 94 \\
\hline Rua São Paulo & 0.62 & 54 & 60 \\
\hline Média & & 69 & 81 \\
\hline
\end{tabular}

Continuação... Tabela 1: Quantificação arbórea realizada 2011utilizando ferramenta Google Street View e 2014 em loco nas principais ruas da cidade de Presidente Epitácio (SP).

Considerando o número de árvores por $10 \mathrm{~m}$ de rua, observa-se que houve um aumento de $6 \%$ do valor médio, passando de 1,27 para 1,35 árvores/10m de rua. Esse aumento também alterou o ordenamento da arborização das ruas, onde em 2011 as ruas com maiores densidades de árvores foram Sebastião Novais, Belo Horizonte e Porto Alegre com 2,06, 1,77 e 1,75 árvores/10m de rua, respectivamente (Figura 4a). Em 2014 essa ordem foi alterada para Fernando Costa, que em 2011 estava em $50^{\circ}$ lugar, Sebastião Novais e Belo Horizonte, com 3,12, 2,36 e 1,83 árvores/10m de rua, respectivamente (Figura $4 b$ ). 
Alvez T. R. S., Vacari T. C., Abreu C. A. A., e Cruz I. F., Aplicação de Ferramentas de Geotecnologia para quantificação arbórea em área urbana. E\&S - Engineering and Science, (2014), 2:1.

Figura 4: Ordenamento da densidade de árvores nas principais ruas da cidade de Presidente Epitácio (SP) em: a) 2011utilizando ferramenta Google Street View e b) 2014 em loco.

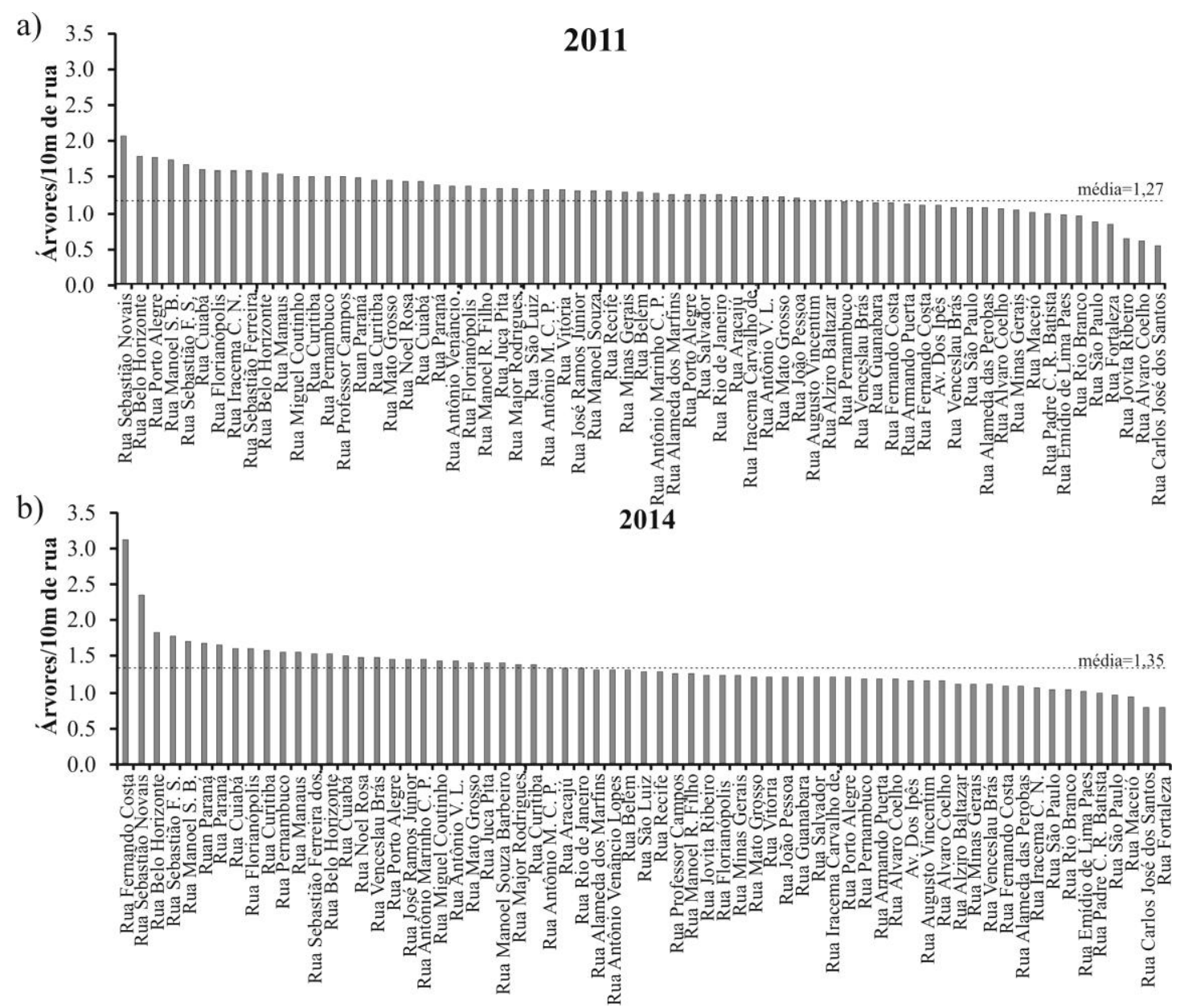

Fonte: Prefeitura de Presidente Prudente

Para a uma comparação mais robusta da evolução da arborização para cada sítio, entre os anos de 2011 e 2014 , um teste $t$ pareado foi aplicado. O teste mostrou que é possível também realizar a comparação da situação da arborização urbana de 2011 para atualmente, 2014.

Pode-se observar que as Paralelas do Lado Maceió (Figura 5a), apresentou um crescimento no número de árvores deste logradouro, porém esta diferença não foi estatisticamente significativa $(t=1,82 ; p=0,10)$. Este padrão também foi observado nas Perpendiculares do lado Maceió (Figura 5b) $(t=1,39$; $p=0,17)$ e Paralelas do Lado Fortaleza (Figura 5c) $\quad(t=0,56 ; \quad p=0,60)$. Nas Perpendiculares do Lado Fortaleza observa-se um aumento de $15 \%$ na densidade de árvores neste logradouro, porém o teste $\mathrm{t}$ pareado mostrou que essa diferença não é significativa $(t=1,92 ; p=0,07)$ (Figura 5d). 
Alvez T. R. S., Vacari T. C., Abreu C. A. A., e Cruz I. F., Aplicação de Ferramentas de Geotecnologia para quantificação arbórea em área urbana. E\&S - Engineering and Science, (2014), 2:1.

Figura 5: Comparação da densidade arbórea entre 2011, utilizando ferramenta Google Street View, e 2014 em loco, das principais ruas identificadas como: a) Paralelas Lado Maceió; b) Perpendiculares Lado Maceió; c) Paralelas Lado Fortaleza; d) Perpendiculares Lado Fortaleza .

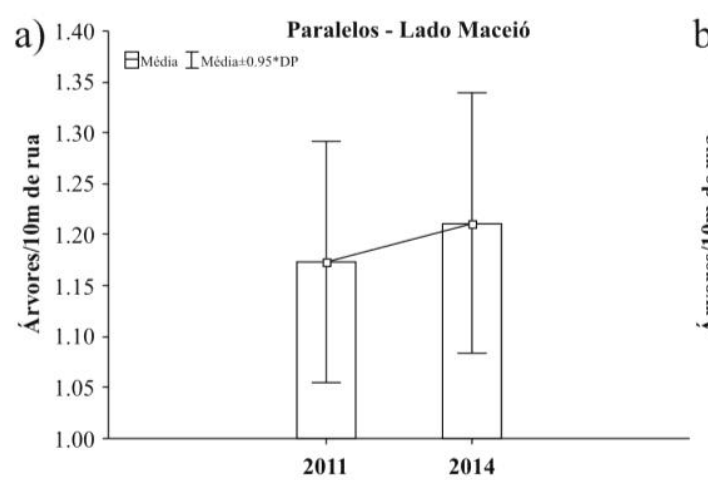

c)

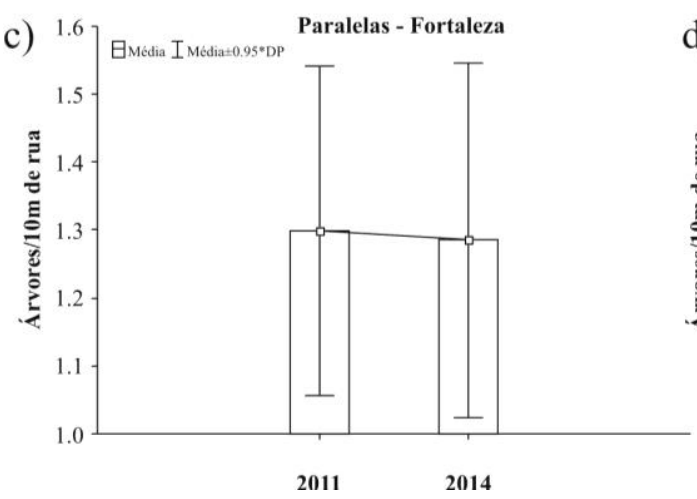

Embora estatisticamente não significativo, ocorreu um aumento no número de árvores na cidade que pode ser considerado pela influencia de ações de educação ambiental nos últimos anos, com a aplicação de diversos programas de incentivo a arborização na cidade como a Semana do Meio Ambiente, o envolvimento de escolas, palestras e plantios comunitários, que incentivaram a população.

Porém, esse plantio sem um plano a ser seguido pode acarretar problemas, como a escolha de espécies não adequadas a áreas urbanas, o que pode, futuramente acarretar problemas ao desenvolvimento urbano. Segundo Almeida e Rondon Neto (2010) a ausência de legislação específica para atender ao planejamento urbano, nessas cidades, pode ter contribuído para essa distribuição irregular das espécies. Dessa forma, a escolha das espécies para a
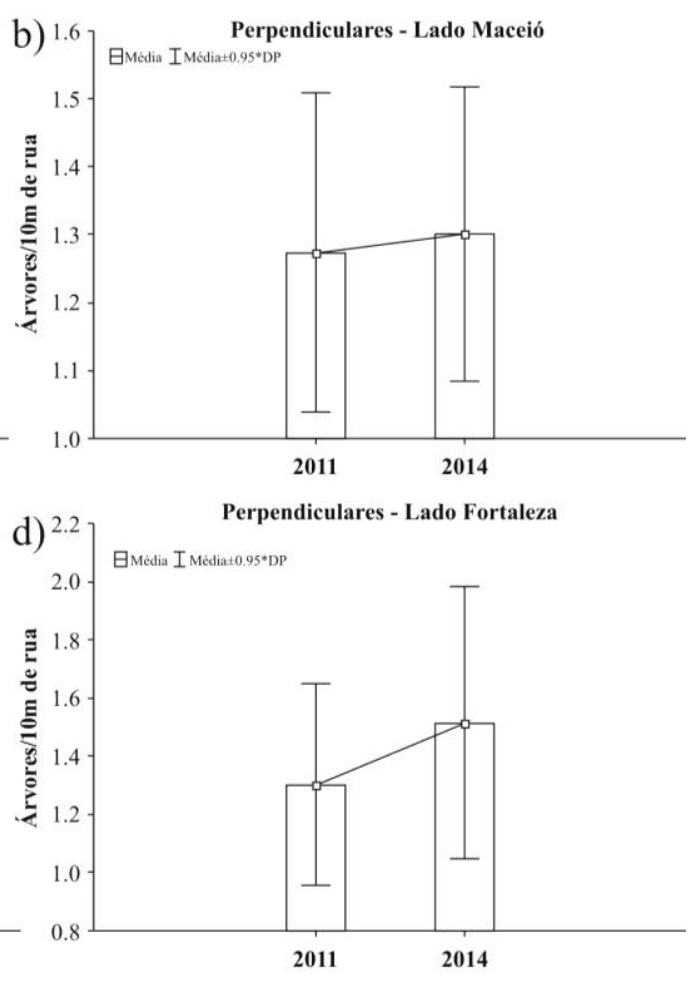

arborização viária fica sobresponsabilidade dos moradores, refletindo no plantio desordenado, sem a observância de critérios técnicos.

De acordo com o Manual Técnico de Arborização Urbana da Secretaria do Meio Ambiente da Prefeitura da São Paulo

(http://www.prefeitura.sp.gov.br/cidade/se cretarias/meio_ambiente/publicacoes_svm a), as espécies essenciais para um Plano de Arborização Urbana devem estar adaptadas ao clima, ter porte adequado ao espaço disponível e também ter forma e tamanho compatíveis com o espaço disponível. Também devem dar frutos pequenos, ter flores pequenas e folhas coriáceas pouco suculentas. Não devem apresentar princípios tóxicos perigosos, apresentar rusticidade e ter sistema radicular que não prejudique 0 calçamento. Além disso, deve evitar 
Alvez T. R. S., Vacari T. C., Abreu C. A. A., e Cruz I. F., Aplicação de Ferramentas de Geotecnologia para quantificação arbórea em área urbana. E\&S - Engineering and Science, (2014), 2:1.

espécies que tornem necessária a poda frequente e estabelecer um numero de espécies a utilizar, ou seja, cada espécie não deve ultrapassar 10 a $15 \%$ da população total de árvores. Para a cidade de Presidente Epitácio, foram encontradas várias árvores fugindo do modelo de uma boa arborização urbana.

Lorenzi (1992, 1998), citado por Pivetta e Silva Filho (2002), identificam dentre inúmeras, as principais espécies que devem ser utilizadas na arborização urbana, cada tal de acordo com a sua adequação, como por exemplo, espécies adequadas para praças, ruas com rede de distribuição elétrica, estacionamentos, canteiros centrais, etc. No caso de Presidente Epitácio, há a predominância de três principais espécies: Licania tomentosa, também chamado oiti da família Chrysobalanaceae; Caesalpinia pluviosa, famosa sibipiruna da família Fabaceae e Pachira aquática, conhecida como monguba da família Malvaceae. Oiti foi a espécie mais encontrada durante o levantamento. Esta é muito utilizada na arborização urbana, por sua copa ser grande possibilitando assim uma ótima sombra.

Um fator importante a ser ressaltado sobre a oiti é a sua reconhecida resistência a poluentes. Já a sibipiruna é uma árvore de grande porte, podendo chegar a uma altura de 28 metros. É uma árvore muito usada na arborização urbana, principalmente na cidade de São Paulo, porém, há um grande risco de ser atacada por pragas como cupins, comprometendo a situação da árvore e causando prejuízos, como a invasão a domicílios próximos, e até mesmo as condições fitossanitárias da própria árvore.

E finalmente a monguba é muito utilizada na arborização urbana, por tais qualidades como estética de copa densa e arredondada. Porém, não é uma espécie recomendada, pelo fato de a árvore procurar locais úmidos, dado em seu nome de "aquatica", podendo assim invadir domicílios em suas redes de distribuição de água e coleta de esgoto, causando assim muitos prejuízos.

Outro importante problema a ser destacado são as podas drásticas, onde na maioria não são realizadas adequadamente, com a remoção total da copa. Romani et al. (2012), também encontraram problemas relacionados a podas inadequadas que podem ocasionar a morte da planta e uma série de problemas.

A fiscalização tem grande influência na cidade, pois para que os moradores possam realizar poda ou supressão, devem retirar uma autorização no CEA (Centro de Estudos Ambientais) da Prefeitura de Presidente Epitácio. O responsável pela autorização realiza uma vistoria, e assim se a árvore realmente está acarretando problemas ao morador, será aceita tal atividade.

\section{Conclusões}

A arborização na cidade de Presidente Epitácio (SP) apresentou diversos problemas relacionados no uso de espécies inadequadas. Percebeu-se uma falta de informações aos moradores, quanto ao realizar o plantio de árvores em seus domicílios, fazendo com que plantassem estas sem conhecimento, acarretando problemas futuros.

Outro fator foi $\mathrm{o}$ aumento da quantidade de árvores, entre 2011 e 2014, podendo ser explicado pela aplicação de programas de incentivo pela Prefeitura da cidade, a fiscalização e a própria conscientização dos moradores.

A estratégia para melhorar a arborização da cidade seria um projeto de arborização, ou seja, a implantação de um Plano Municipal de Arborização Urbana que poderia estar previsto no Plano Diretor da cidade. A implantação deste plano requer muitos estudos, realizando 
Alvez T. R. S., Vacari T. C., Abreu C. A. A., e Cruz I. F., Aplicação de Ferramentas de Geotecnologia para quantificação arbórea em área urbana. E\&S - Engineering and Science, (2014), 2:1.

consultas com órgãos responsáveis, levantamento da situação existente e a importante participação da população local. Pode-se contar também com a contínua fiscalização e influência da mídia, propagando a importância da existência de árvores no meio urbano.

\section{Agradecimentos}

A prefeitura da cidade de Presidente Epitáfio (SP), pela concessão do estágio, que oportunizou a realização deste trabalho. A colaboração das professoras Margarida Marchetto e Karina Tondato pelas valiosas contribuições ao texto.

\section{Referências}

Almeida DN, Rondon NRM. (2010) Análise da arborização urbana de duas cidades da região norte do estado de Mato Grosso. Rev. Árvore [online], vol.34, n.5, pp. 899-906. doi: 10.1590/S010067622010000500015

Brito DRS, Raabe J, Sousa WC, Pedrosa TD. (2012) Diagnóstico da arborização das praças públicas no munícipio de Bom Jesus, Piauí. Scientia Plena, vol.8, n.4, pp. 1- 6 .

BARTHOLOMEI, C. L. B. Influência da vegetação no conforto térmico urbano e no ambiente construído. Tese (Doutorado em Saneamento e Ambiente) - Faculdade de Engenharia Civil, Universidade Estadual de Campinas. 186 p, Campinas, 2003.

Faria DC, Duarte JMA, Pinto DM, Almeida FS. (2013) Arborização Urbana no Município de Três Rios - RJ: Espécies utilizadas e a Percepção de seus Benefícios pela População. REVISBAU, vol.8, n.2, p58-67.

GUZZO, P - Estudo dos espaços livres de uso publico da cidade de Ribeirão Preto/SP, com detalhamento da cobertura vegetal e áreas verdes de dois setores urbanos. Dissertação (Mestrado em Geociências e Meio Ambiente), UNESP - Universidade Estadual Paulista, Rio Claro, 1999.

Lima SFS. (2011) Iniciação em Sensoriamento Remoto. Educar em Revista, n. 40, p. 225-227, mai./ago.

Loboda CR. Anhelis BLD. (2005) Áreas verdes públicas urbanas: conceitos, usos e funções. Ambiência Guarapuava, PR. v.1 n.1 p. 125-139 jan./jun.

Pivetta KFL, Silva FDF. (2002) Arborização urbana. Jaboticabal: UNESP/FCAV/FUNEP. (Boletim Acadêmico. Série Arborização Urbana).

Platt RH. (1994) The ecological city: introduction and overview. In: Platt RH, Rowan AR, Muick PC. The ecological city: preserving and restoring urban biodiversity. Amherst: The University of Masschusetts Press, 291p.

Romani, GN, Gimenes R, Silva MT, Pivetta KFL, Batista GS. (2012). Análise quali-quantitativa da arborização na praça XV de novembro em Ribeirão Preto - SP, Brasil. Rev. Árvore [online], vol.36, n.3, pp. 479-487. doi:10.1590/S010067622012000300010

Rosa R. (2011) O uso de tecnologias de informação geográfica no Brasil, Revista Geográfica da América Central, Número Especial EGAL.

SANCHOTENE, M. do C.C. Desenvolvimento e perspectivas da Arborização urbana no Brasil. In: Congresso Brasileiro de Arborização Urbana, 2, 1994. São Luís-MA. Anais... São Luís, Sociedade Brasileira de Arborização Urbana; 1994.

SÃO PAULO. Manual Técnico de Arborização - Prefeitura da São Paulo. 2002. 